\title{
Effect of orthodontic treatment on saliva, plaque and the levels of Streptococcus mutans and Lactobacillus
}

\author{
Edith Lara-Carrillo ${ }^{1}$, Norma-Margarita Montiel-Bastida ${ }^{2}$, Leonor Sánchez-Pérez ${ }^{3}$, Jorge Alanís-Tavira ${ }^{4}$
}

\author{
${ }^{1}$ DDS, MSD Doctoral student; Department of Orthodontics, Research Center, School of Dentistry, Universidad Autónoma del \\ Estado de México, Toluca, Estado de México, Mexico \\ ${ }^{2}$ DDS, PhD Professor and Head, Research Center, School of Dentistry, Universidad Autónoma del Estado de México, Toluca, \\ Estado de México, Mexico \\ ${ }^{3}$ DDS, MSD, PhD Professor, Health Attention Department, Universidad Autónoma Metropolitana Unidad Xochimilco, Mexico \\ City, Mexico \\ ${ }^{4}$ DDS, MSD, PhD Professor, Research Center, School of Dentistry, Universidad Autónoma del Estado de México, Toluca, Estado \\ de México, Mexico
}

Correspondence:

Facultad de Odontología de la UAEM

Centro de Investigación y Estudios Avanzados en Odontología

Paseo Tollocan esq. Jesús Carranza, Col. Universidad

C.P. 50130, Toluca, Estado de México. México

laracaedith@hotmail.com

Received: $11 / 09 / 2009$

Accepted: 21/02/2010
Lara-Carrillo E, Montiel-Bastida NM, Sánchez-Pérez L, Alanís-Tavira J. Effect of orthodontic treatment on saliva, plaque and the levels of Streptococcus mutans and Lactobacillus. Med Oral Patol Oral Cir Bucal. 2010 Nov 1;15 (6):e924-9.

http://www.medicinaoral.com/medoralfree01/v15i6/medoralv15i6p924.pdf

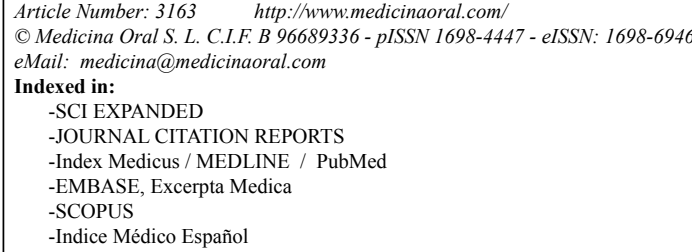

\begin{abstract}
Objectives: The aim of this study was to identify changes in the oral environment with clinical, salivary and bacterial risk markers after placement of fixed orthodontic appliances on permanent dentition.

Material and Methods: With ethical approval, we used different techniques to analyzed clinical, salivary and bacterial risk markers in 34 patients (mean age, $16.7 \pm 5.2$ years), 14 males and 20 females; before starting orthodontic treatment and 1 month after. Clinical risk markers (decayed, missing, and filled surfaces [DMFS], O'Leary's plaque index, and plaque $\mathrm{pH}$ ); salivary markers (unstimulated and stimulated saliva flow rate, buffer capacity, $\mathrm{pH}$, and occult blood in saliva) and bacterial counts (Streptococcus mutans and Lactobacillus). Data were analyzed by paired t-test and $\chi^{2}$ test.

Results: This study showed that orthodontic appliances increased the stimulated salivary flow rate $(\mathrm{p}=0.0001)$, buffer capacity $(\mathrm{p}=0.0359)$, salivary $\mathrm{pH}(\mathrm{p}=0.0246)$ and occult blood in saliva $(\mathrm{p}=0.0305)$. Bacterial levels increased slightly after 1 month of treatment, without statistical significance. Between genders, initially we observed differences in: stimulated saliva $(\mathrm{p}=0.0019)$, buffer capacity $(\mathrm{p}=0.0381)$ and plaque $\mathrm{pH}(\mathrm{p}=0.0430)$; after treatment the unstimulated saliva $(\mathrm{p}=0.0026)$ showed differences.

Conclusions: Orthodontic treatment changes the oral environmental factors, promotes an increase in stimulated flow rate, buffer capacity and salivary $\mathrm{pH}$, which augment the anti caries activity of saliva. In contrast, increased occult blood indicated more gingival inflammation, apparently because augmented the retentive plaque surfaces and the difficult to maintain a good oral hygiene, rinsed the bleeding in saliva by periodontal damage.
\end{abstract}

Key words: Saliva, oral health, orthodontic treatment. 


\section{Introduction}

Malocclusions are the 3rd most common of oral health problems, and are associated with a number of complications (1). Orthodontic treatment often can correct these complications or at least prevent them from progressing; but it also holds some potential for harm to teeth and periodontal tissues. For example oral hygiene may be difficult to maintain during treatment, which may lead to plaque accumulation and gingival inflammation (2). It has been shown that orthodontic treatment induces changes in the oral environment, with an increase in the bacteria's concentration, and alterations in buffer capacity, $\mathrm{pH}$ acidity and salivary flow rate (3); however, little is known about periodontal inflammation that results in occult blood in saliva and the acidity of dental plaque.

Considerable time and effort has been spent on developing tests to identify individuals at risk for developing dental caries and periodontal damage. Diverse tests exist based predominantly on quantitative estimation of Streptococcus mutans and Lactobacillus, and on determination of quantity and quality of saliva (4-6).

The caries activity test Cariostat ${ }^{\circledR}$ (Dentsply-Sankin KK, Tokyo, Japan) developed by Shimono, was designed to measure the decrease of $\mathrm{pH}$ caused by bacterial action in the dental plaque. It has been reported positive correlations between caries activity test score and the counts of Streptococcus mutans and Lactobacillus (7).

Actually exist another colorimetric salivary test used as indicator at inflammation which involves determining occult blood derived from the gingival tissue for evaluates periodontal disease in initial stages, called Salivaster $^{\circledR}$ (Showa Yakuhin Kako Co. LTD, Tokyo, Japan) $(8,9)$.

It is important to identify the changes in the oral environment in patients undergoing orthodontic treatment with fixed appliances. In some cases involving long treatment duration, the clinicians are committed to preserving the oral health of the patient. Actually, there exist few clinical studies that show the physiologic and biological characteristics of saliva and the correlation with clinical specific entities.

Therefore, the aim of the present study was to identify changes in the oral environment with clinical, salivary and bacterial risk markers after placement of fixed orthodontic appliances on permanent dentition.

\section{Material and Methods}

Patients who required treatment with fixed orthodontic appliances (straight wire technique) from the Orthodontic Clinic at the Research Center and Advanced Studies in Dentistry of the Autonomous University of the State of Mexico (UAEM) were studied. Thirty-four patients: 14 males (mean age, $16.2 \pm 3.4$ years) and 20 females (mean age, $17.2 \pm 6.3$ years) participated. These patients didn't have any systemic diseases, use of antibiotics at least 15 days before initiating the study, active caries, and on mixed dentition phase were excluded. This research was approved by the Ethics Committee of the University. All patients or their tutors consented to participate after obtaining information about the study.

Samples were taken from each patient in two stages, one before beginning the orthodontic treatment and the other 1 month after placement of the appliances, because this is the time for the appointment to change the first arch wire. The orthodontics attachments were placed in both arches.

The patients avoided eating or drinking and no tooth brushing at least 2 hours before taking the samples in both stages. All procedures were done by one calibrated researcher, and commercial kits were used according to the manufacturer's instructions.

Intraexaminer reliability in using these kits and all markers was tested prior to the study using a group of orthodontic patients from one author's (NMMB) clinical practice. Dental and skeletal diagnoses were obtained from each patient, defined by Angle's molar class and the subspinale-nasion-supramentale cephalometric angle (ANB).

Recommendations to avoid retentive, cariogenic, or hard foods during orthodontic treatment were provided verbally. We recommended that patients brush their teeth three times a day using the Bass modified technique with toothpaste containing fluoride after placement of appliances.

2.1 Clinical markers

- The decayed, missing and filling surfaces index (DMFS) was recorded according to criteria of the World Health Organization for permanent dentition.

- The supragingival plaque was disclosed with a chewable tablet (Viarden ${ }^{\circledR}$; Viarden, Mexico City, Mexico) and its amount estimated using criteria according to O'Leary's plaque index $(10,11)$.

Clinical markers only were measurement at the beginning of the study.

\subsection{Salivary markers}

- Unstimulated saliva was the formation time (in seconds) of small saliva drops in the inner mucous of the lower lip (Saliva Check $^{\circledR}$, GC America Inc., Alsip, IL, USA) (6).

- Stimulated saliva was the total stimulated saliva obtained during 5 minutes by chewing an unflavored piece of wax; the result was expressed in $\mathrm{mL} / \mathrm{min}$ (6).

- Buffer capacity was determined by placing stimulated saliva using a pipette, dispensed one drop onto each of the 3 test pads in the reactive strip of the Saliva Check $^{\circledR}$ test. After 2 minutes, the final result was calculated by adding the points according to the final colour of each pad: very low $=0$ to 5 points; low $=6$ to 9 points; and normal/high $=10$ to 12 points (6). 
- To determine salivary $\mathrm{pH}$, the reactive strip of the Saliva Check $^{\circledR}$ was submerged in stimulated saliva for 10 seconds, the color obtained was compared with the chart: highly acidic $=5.0$ to 5.8 ; moderately acidic $=6.0$ to 6.6 ; and healthy saliva $=6.8$ to $7.8(6)$.

\subsection{Bacterial markers}

- To estimate the number of colony-forming units of Streptococcus mutans counts (SM) per milliliter of saliva $\left(\mathrm{CFU} / \mathrm{mL}\right.$ ) was used Dentocult ${ }^{\circledR}$ SM (Orion Diagnostica, Espoo, Finland) according to Jensen and Bratthall (4). Counts were categorized as follows score: 0 $=$ negative or $<104$ colony-forming units $(\mathrm{CFU}) / \mathrm{mL}, 1$ $=10^{5} \mathrm{CFU} / \mathrm{mL}, 2=10^{5}$ to $10^{6} \mathrm{CFU} / \mathrm{mL}$, and $3=>10^{6}$ $\mathrm{CFU} / \mathrm{mL}$

- The number of Lactobacillus was obtained by the use of Dentocult ${ }^{\mathbb{B}}$ LB (Orion Diagnostica, Espoo, Finland), described by Larmas $(5,12)$. The growth densities were categorized as follows: $\mathrm{NC}=$ no count, $0=$ negative or $10^{3} \mathrm{CFU} / \mathrm{mL}, 1=10^{4} \mathrm{CFU} / \mathrm{mL}, 2=10^{5} \mathrm{CFU} / \mathrm{mL}$, and 3 $=10^{6} \mathrm{CFU} / \mathrm{mL}$.

2.4 Plaque $\mathrm{pH}$

- The ability of dental plaque to produce acid $(\mathrm{pH})$ was determined by Cariostat ${ }^{\mathbb{B}}$ (Dentsply-Sankin KK, Tokyo, Japan). Plaque was collected from buccal surfaces of first upper molars, using a sterilized cotton swab supplied in the kit, which was put into a test medium and incubated. The test color change was compared with the pattern provided by the manufacturer as follows: negative value $=\mathrm{pH}$ 5.8-7.2; one positive value $=\mathrm{pH} 5.4 \pm 0.3$; two positives value $=\mathrm{pH} 4.8 \pm 0.3$ and three positives value $=\mathrm{pH}<4.4(7,13)$.

2.5 Occult blood in saliva

- To measure occult blood, the Salivaster ${ }^{\circledR}$ reactive strip (Showa Yakuhin Kako Co. LTD, Tokyo, Japan) was used. The procedure involves dipping the test paper in stimulated saliva for 2-3 seconds and then judging by comparing to the standard color change chart, divided into 3 levels: without change $=0.0 \mathrm{mg}$ of blood per $\mathrm{dL}$ of saliva (no periodontal disease), light blue $=1.0 \mathrm{mg} / \mathrm{dL}$ (incipient periodontal disease), and dark blue $=2.5 \mathrm{mg}$ / dL (periodontal disease present) (9).

Statistical analysis

Clinical data were only obtained before treatment (DMFS and plaque index). For the other variables a paired t-test or $\chi^{2}$ test were used to determine significant differences between the first and second samples, and between genders. The information was analyzed using JMP 7.0 (SAS Institute Inc., Cary, NC, USA). The statistical level of significance was set at 0.05 .

\section{Results}

Thirty-four subjects participated in this study. Fifteen patients had molar relation class I, fourteen had class II, four had class III, and in one patient it was not possible to determine the relationship due to absent first molars.
As for the skeletal diagnosis, fourteen were class I, nineteen were class II, and one were class III. The dental and skeletal diagnoses were not associated or determined the behavior of any of the studied variables $(\mathrm{p}>0.05)$ (data not shown).

\section{Clinical markers}

The mean DMFS index of the subjects was 6.47, although it was greater in females (8.70) that in males (3.28), these differences were not statistically significant $(\mathrm{p}=0.1352)$. The mean O'Leary's plaque index was $44.6 \%$, males presented a slightly greater plaque percentage $(50.84 \%)$ than females $(40.15 \%)(\mathrm{p}=0.1809)$.

\section{Salivary markers}

We did not find statistically significant differences in the unstimulated salivary production before and 1-month after the placement of orthodontic appliances, nevertheless in the second stage there were differences between gender in salivary rate $(\mathrm{p}=0.0026)$; specifically, the unstimulated salivary production was lower in women (Table 1).

The placement of orthodontic appliances promoted a major stimulated salivary flow in the subjects, with significant differences in the salivary production before and after treatment $(\mathrm{p}=0.0001)$. The salivary stimulated flow rate was greater in males at the beginning of the treatment $(\mathrm{p}=0.0019$; (Table 1$)$.

The salivary buffer capacity showed differences after placement of appliances $(\mathrm{p}=0.0359)$ and between genders before treatment $(p=0.0381)$, females showed lower capacity (Table 1).

Significant differences were observed in the salivary $\mathrm{pH}$ before and after treatment $(\mathrm{p}=0.0246)$ with an increase of the $\mathrm{pH}$ value (Table 1).

\section{Bacterial markers}

We observed changes in the CFU of SM after placement of appliances. Before treatment 14/34 subjects had high values $\left(>10^{5}\right)$; after one month of banding, 16/34 had high values.

In the first sample $7 / 34$ subjects had high levels $\left(>10^{5}\right)$ of Lactobacillus, in the second stage we found 20/34 subjects in these same level, although statistically significant differences were not observed in this distribution ( $\mathrm{p}=0.6905$; (Table 2).

\section{Plaque $p H$}

The acidity of the initial plaque no registered significant modifications after placement of appliances $(p=0.5467)$; however, we found differences between genders in the initial sample $(\mathrm{p}=0.0430)$; with negative values predominating in females, and one positive values in males. The second sample showed more subjects with one positive values in both genders (Table 2).

Occult blood in saliva

Differences were observed in the gingival bleeding before and after orthodontic treatment $(\mathrm{p}=0.0305)$, in the second stage the bleeding in saliva increased. In the 
Table 1. Distribution of salivary markers by gender in the study $(n=34)$.

\begin{tabular}{|l|c|c|c|c|}
\hline \multirow{2}{*}{ Marker } & \multirow{2}{*}{ Gender } & \multicolumn{2}{|c|}{ Stages } & \multirow{2}{*}{$\mathrm{p}^{\mathrm{a}}$} \\
\cline { 3 - 5 } & & Before & After & \\
\hline Salivary markers & & & & \\
\hline \multirow{3}{*}{ Unstimulated saliva (seconds) } & Male & $39.85 \pm 19.17$ & $38.64 \pm 14.90$ & \\
\cline { 2 - 5 } & Female & $45.65 \pm 19.03$ & $57.35 \pm 17.43$ & 0.4073 \\
\cline { 2 - 5 } & $\mathrm{p}^{\mathrm{b}}$ & 0.3903 & $0.0026^{*}$ & \\
\hline \multirow{3}{*}{ Stimulated saliva (mL/min) } & Male & $1.72 \pm 0.65$ & $1.76 \pm 0.80$ & \\
\cline { 2 - 5 } & Female & $1.06 \pm 0.48$ & $1.36 \pm 0.50$ & $0.0001^{*}$ \\
\cline { 2 - 5 } & $\mathrm{p}^{\mathrm{b}}$ & $0.0019^{*}$ & 0.0835 & \\
\hline \multirow{3}{*}{ Buffer capacity } & Male & $8.78 \pm 2.19$ & $8.71 \pm 2.16$ & \\
\cline { 2 - 5 } & Female & $6.90 \pm 2.69$ & $7.70 \pm 1.59$ & $0.0359^{*}$ \\
\cline { 2 - 5 } & $\mathrm{p}^{\mathrm{b}}$ & $0.0381^{*}$ & 0.1247 & \\
\hline \multirow{3}{*}{ Salivary $\mathrm{pH}$} & $\mathrm{Male}^{\mathrm{N}}$ & $7.68 \pm 0.17$ & $7.74 \pm 0.09$ & \\
\cline { 2 - 5 } & Female & $7.53 \pm 0.38$ & $7.73 \pm 0.09$ & $0.0246^{*}$ \\
\hline & $\mathrm{p}^{\mathrm{b}}$ & 0.1672 & 0.7039 & \\
\hline
\end{tabular}

Data shown as mean $+\mathrm{SD}$

pa value between before vs. after placement of appliances, based on paired t-test $\mathrm{pb}$ value between genders, based on paired t-test $* \mathrm{p}<0.05$

Table 2. Distribution of bacterial markers, plaque $\mathrm{pH}$ and occult blood in saliva by gender in the study $(\mathrm{n}=34)$.

\begin{tabular}{|c|c|c|c|c|}
\hline \multirow[b]{2}{*}{ Marker } & \multirow[b]{2}{*}{ Gender } & \multicolumn{2}{|c|}{ Stages } & \multirow[b]{2}{*}{$\mathbf{p}^{\mathbf{a}}$} \\
\hline & & Before & After & \\
\hline \multicolumn{5}{|l|}{ Salivary markers } \\
\hline \multirow{3}{*}{ Unstimulated saliva (seconds) } & Male & $39.85 \pm 19.17$ & $38.64 \pm 14.90$ & \\
\hline & Female & $45.65 \pm 19.03$ & $57.35 \pm 17.43$ & 0.4073 \\
\hline & $\mathbf{p}^{\mathbf{b}}$ & 0.3903 & $0.0026 *$ & \\
\hline \multirow{3}{*}{ Stimulated saliva (mL/min) } & Male & $1.72 \pm 0.65$ & $1.76 \pm 0.80$ & \\
\hline & Female & $1.06 \pm 0.48$ & $1.36 \pm 0.50$ & $0.0001 *$ \\
\hline & $\mathbf{p}^{\mathbf{b}}$ & $0.0019 *$ & 0.0835 & \\
\hline \multirow{3}{*}{ Buffer capacity } & Male & $8.78 \pm 2.19$ & $8.71 \pm 2.16$ & \\
\hline & Female & $6.90 \pm 2.69$ & $7.70 \pm 1.59$ & $0.0359 *$ \\
\hline & $\mathbf{p}^{\mathbf{b}}$ & $0.0381 *$ & 0.1247 & \\
\hline \multirow{3}{*}{ Salivary $\mathrm{pH}$} & Male & $7.68 \pm 0.17$ & $7.74 \pm 0.09$ & \\
\hline & Female & $7.53 \pm 0.38$ & $7.73 \pm 0.09$ & $0.0246 *$ \\
\hline & $\mathbf{p}^{\mathbf{b}}$ & 0.1672 & 0.7039 & \\
\hline
\end{tabular}

$\mathrm{NC}=$ negative at culture

pa value between before vs. after placement of appliances,

based on X2 test

$\mathrm{pb}$ value between genders, based on X2 test

* $\mathrm{p}<0.05$ 
beginning of the study most of the subjects were in the intermediate level with $1 \mathrm{mg} / \mathrm{dL}$ of occult blood in saliva (incipient periodontal disease), however one month later the periodontal disease present increased (Table 2).

\section{Discussion}

This study shows the changes in clinical, salivary and bacterial markers that occur in the oral environment at the beginning of orthodontic treatment with fixed appliances on permanent dentition.

The following markers emerged as protective factors: patients without active caries injuries increased significantly stimulated salivary flow, buffer capacity, and salivary $\mathrm{pH}$, after placement orthodontic appliances. In contrast, the following markers were negative risk factors to the oral environment: slightly increase in the infection levels of SM and Lactobacillus, and of occult blood in saliva.

Oral environment has the capacity of adjustment to the presence of a foreign body, increasing the salivary flow which contributes to the autoclisis and modifying the salivary composition to raise the $\mathrm{pH}$ and buffer capacity, it prevents colonization by potentially pathogenic microorganisms by denying them optimization of enviromental conditions.

In the present study, stimulated salivary flow was greater in males, which is similar to international reports $(3,14,15)$. The differences have been attributed to two theories: women present smaller salivary glands in comparison with men and the female hormonal pattern may contribute to diminished salivary secretion. The mean salivary flow rate for both genders was found in normal parameters: $1-3 \mathrm{~mL} / \mathrm{min}$ in stimulated saliva and from $0.25-0.35 \mathrm{~mL} / \mathrm{min}$ in unstimulated saliva (16). The variability of salivary flow rate has been established by other researchers (14-17). Mechanical or chemical stimulus is associated with increased salivary secretion, our results support a direct and prolonged stimulatory effect after one month of treatment with fixed orthodontic appliances on salivary flow.

Salivary buffer capacity presented a significant increase in females after orthodontic therapy, situation that has been reported by Chang et al. (3). Males showed higher buffer capacity than females, this difference between genders have been demonstrated previously (16). This salivary function avoids the settling of pathogenic microorganisms in mouth and neutralizes the acids produced by acidogenic bacterias, preventing enamel desmineralization. This is one of the best risk indicators, because it reveals the host response (5). Patients with a high buffer capacity are often quite resistant to the caries process, because high host response can even compensate for active caries habits. If orthodontic patient at high caries risk can be identified at the beginning of treatment, preventive measures can be implemented with maximal effect.
Salivary $\mathrm{pH}$ demonstrated a significant increase in the 1st month of treatment, as opposed to other studies in which it has been established that $\mathrm{pH}$ suffers alterations after 3 months of orthodontic treatment (3). Orthodontic appliances increase the retentive plaque surfaces, causing elevated acid levels of concentration of hydrogen ions in oral environment, then the $\mathrm{pH}$ decrease. However, we observed higher flows of stimulated salivary secretion, which raise the concentration of bicarbonate ions, then the $\mathrm{pH}$ also rises and the buffering power of the saliva increases dramatically; demonstrating the physiologic response to maintain the oral health in adverse situations.

In this study, clinical markers showed that males had lower DMFS index and higher O'Leary's plaque index than females. Males showed more acid plaque $\mathrm{pH}$ at the beginning of treatment, nevertheless an increase in acidity was demonstrated 1 month later in females. The plaque $\mathrm{pH}$ had significant differences between genders when the patients already were in orthodontic treatment. The orthodontic appliances protected the plaque from the tooth brushing action, the mastication, and the salivary fluid. Accumulating more on the cervical region of the brackets or below the arches wire, which is the area where a major demineralization can be found (18). The plaque control is one of the most important factors that limit the implantation and settling of causal microorganisms from caries and periodontal disease. In relation to bacterial counts, the present study showed a slightly increase of colony formation, after placement of appliances, as opposed to report previously (3). However, the increase of retentive plaque surfaces might cause a higher risk for the patient during the treatment, because exist some stages in which more orthodontic appliances can include.

Before initiating treatment, the majority of patients showed incipient periodontal disease, possibly caused by crowding, which is the principal motivation for the orthodontic treatment. Likewise, a significant increase of periodontal disease was observed 1 month after initiating orthodontic therapy $(2.5 \mathrm{mg} / \mathrm{dL}$ of saliva). According to reported in the literature, the adjacent connective tissue inflammation has been considered a consequence of the use of orthodontic bands, determining that the condition of the gum deteriorates during the treatment with fixed appliances, even in patients with good oral hygiene (1). Several preventive strategies relating to changes in the oral environment in orthodontic patients were established. Checking the quality, $\mathrm{pH}$ and buffer capacity of saliva can be valuable as part of an overall clinical assessment, thus also monitoring bacterial counts, plaque and periodontal inflammation. 


\section{Conclusions}

Orthodontic treatment changes the oral environmental factors: promotes a major salivary stimulated flow and increases its buffer capacity and salivary $\mathrm{pH}$, which increase the anticaries activity of saliva.

Plaque $\mathrm{pH}$ did not demonstrate significant changes before and 1-month into orthodontic treatment. The bacterial levels did not increase significantly in the first month of the orthodontic treatment but, the increase of retentive plaque surfaces and the difficult to remove it, rinsed the bleeding in saliva by periodontal injury.

It is necessary to maintain the balance between the protective factors and the caries risk factors during the orthodontic treatment with a rigorous home care program toward correct oral hygiene procedures necessary to control plaque accumulation for caries and periodontal disease prevention.

\section{References}

1. Glans R, Larsson E, Ogaard B. Longitudinal changes in gingival condition in crowded and noncrowded dentitions subjected to fixed orthodontic treatment. Am J Orthod Dentofacial Orthop. 2003;124:679-82.

2. Bollen AM, Cunha-Cruz J, Bakko DW, Huang GJ, Hujoel PP. The effects of orthodontic therapy on periodontal health: a systematic review of controlled evidence. J Am Dent Assoc. 2008;139:413-22.

3. Chang HS, Walsh LJ, Freer TJ. The effect of orthodontic treatment on salivary flow, $\mathrm{pH}$, buffer capacity, and levels of mutans streptococci and lactobacilli. Aust Orthod J. 1999;15:229-34.

4. Jensen B, Bratthall D. A new method for the estimation of mutans streptococci in human saliva. J Dent Res. 1989;68:468-71.

5. Larmas M. Saliva and dental caries: diagnostic tests for normal dental practice. Int Dent J. 1992;42:199-208.

6. Varma S, Banerjee A, Bartlett D. An in vivo investigation of associations between saliva properties, caries prevalence and potential lesion activity in an adult UK population. J Dent. 2008;36:294-9.

7. Nishimura M, Oda T, Kariya N, Matsumura S, Shimono T. Using a caries activity test to predict caries risk in early childhood. J Am Dent Assoc. 2008;139:63-71.

8. Hashimoto M, Yamanaka K, Shimosato T, Ozawa A, Takigawa T, Hidaka S, et al. Oral condition and health status of elderly 8020 achievers in Aichi Prefecture. Bull Tokyo Dent Coll. 2006;47:37-43. 9. Niwa M, Fukuda M. Clinical study on the control of dental plaque using a photo energy conversion toothbrush equipped with a $\mathrm{TiO} 2$ semiconductor. Shigaku. 1989;77:598-606.

10. O'Leary TJ, Drake RB, Naylor JE. The plaque control record. J Periodontol. 1972;43:38.

11. Butler BL, Morejon O, Low SB. An accurate, time-efficient method to assess plaque accumulation. J Am Dent Assoc. 1996;127:1763-6.

12. Birkhed D, Edwardsson S, Andersson H. Comparison among a dip-slide test (Dentocult), plate count, and Snyder test for estimating number of lactobacilli in human saliva. J Dent Res. 1981;60:183241.

13. Ansai T, Yamashita Y, Shibata Y, Katoh Y, Sakao S, Takamatsu $\mathrm{N}$, et al. Relationship between dental caries experience of a group of Japanese kindergarten children and the results of two caries activity tests conducted ontheir saliva and dental plaque. Int J Paediatr Dent. 1994;4:13-7.

14. Bretz WA, Do Valle EV, Jacobson JJ, Marchi F, Mendes S, Nor JE, et al. Unstimulated salivary flow rates of young children. Oral Surg Oral Med Oral Pathol Oral Radiol Endod. 2001;91:541-5.

15. De Almeida Pdel V, Grégio AM, Machado MA, De Lima AA, Azevedo LR. Saliva composition and functions: a comprehensive review. J Contemp Dent Pract. 2008;9:72-80.
16. Elishoov H, Wolff A, Kravel LS, Shiperman A, Gorsky M. Association between season and temperature and unstimulated parotid and submandibular/sublingual secretion rates. Arch Oral Biol. 2008;53:75-8.

17. Torres SR, Nucci M, Milanos E, Pereira RP, Massaud A, Munhoz T. Variations of salivary flow rates in Brazilian school children. Braz Oral Res. 2006;20:8-12.

18. Gwinnett AJ, Ceen RF. Plaque distribution on bonded brackets: a scanning microscope study. Am J Orthod. 1979;75:667-77.

\section{Acknowledgments}

We thank to the National Council of Science and Technology of Mexico (CONACYT) for their support. 